\title{
Diagnosis and treatment of $\mathrm{TB}$ patients with rifampicin resistance detected using $X$ pert $^{\circledR}$ MTB/RIF in Zimbabwe
}

\author{
K. Charambira, ${ }^{1}$ S. Ade, ${ }^{2,3}$ A. D. Harries, ${ }^{2,4}$ R. T. Ncube, ${ }^{1}$ C. Zishiri, ${ }^{1}$ C. Sandy, ${ }^{5}$ H. Mutunzi, ${ }^{5}$ \\ K. Takarinda, ${ }^{2,5}$ P. Owiti, ${ }^{2}$ P. Mafaune, ${ }^{5}$ P. Chonzi 6
}

http://dx.doi.org/10.5588/pha.16.0005

Setting: In Zimbabwe, there are concerns about the management of tuberculosis (TB) patients with rifampicin (RMP) resistance diagnosed using Xpert ${ }^{\circledR}$ MTB/RIF.

Objective: To assess linkages between diagnosis and treatment for these patients in Harare and Manicaland provinces in 2014.

Design: A retrospective cohort study.

Results: Of 20329 Xpert assays conducted, 90\% were successful, $11 \%$ detected Mycobacterium tuberculosis and $4.5 \%$ showed RMP resistance. Of 77 patients with RMP-resistant TB diagnosed by Xpert, $70 \%$ had samples sent to the reference laboratory for culture and drug susceptibility testing (CDST); $53 \%$ of the samples arrived. In $21 \%$ the samples showed M. tuberculosis growth, and in $17 \%$ the DST results were recorded, all of which confirmed RMP resistance. Of the 77 patients, 34 (44\%) never started treatment for multidrug-resistant (MDR) TB, with documented reasons being death, loss to follow-up and incorrect treatment. Of the 43 patients who started MDR-TB treatment, 12 (71\%) in Harare and 17 (65\%) in Manicaland started within 2 weeks of diagnosis.

Conclusion: Xpert has been rolled out successfully in two Zimbabwe provinces. However, the process of confirming CDST for Xpert-diagnosed RMP-resistant TB works poorly, and many patients are either delayed or never initiate MDR-TB treatment. These shortfalls must be addressed at the programmatic level.

Z imbabwe is one of the world's 22 high-burden tuberculosis $(\mathrm{TB})$ countries, with an estimated $\mathrm{TB}$ incidence of 552 per 100000 population in $2013 .{ }^{1} \mathrm{Hu}-$ man immunodeficiency virus (HIV) prevalence is $17 \%$, and $69 \%$ of TB patients are co-infected with HIV. ${ }^{1,2}$ For decades, the diagnosis of pulmonary TB has relied on sputum smear microscopy, although the test lacks sensitivity and does not detect drug-resistant TB. ${ }^{3,4}$ The early diagnosis of multidrug-resistant TB (MDR-TB, defined as TB resistant to at least both rifampicin [RMP] and isoniazid [INH]), is essential to institute prompt treatment, reduce mortality and prevent the transmission of infection. ${ }^{5}$ In this light, the Xpert ${ }^{\circledR}$ MTB/RIF assay (Cepheid Inc, Sunnyvale, CA, USA) is revolutionary, requiring minimal laboratory expertise and yielding test results within 2 hours. ${ }^{6}$ Sensitivity and specificity for TB diagnosis is high, and the assay also detects RMP resistance. Studies in several settings have shown the feasibility, accuracy and effectiveness of Xpert, $^{7}$ prompting the World Health Organization (WHO) in 2010 to strongly recommend the wide- spread use of Xpert, with priority for those with suspected MDR-TB and for patients with TB and HIV coinfection..$^{8,9}$ In 2013, the WHO made a conditional recommendation that Xpert should be the initial diagnostic test for all people requiring investigation for TB. 10

Zimbabwe has been scaling up the implementation of Xpert since 2011. By December 2014, 62 sites in the country were using this technology. All individuals identified with RMP-resistant TB by Xpert should be placed immediately on treatment for MDR-TB, and their specimens should be processed for culture and drug susceptibility testing (CDST), in line with previous $\mathrm{WHO}$ recommendations. ${ }^{9}$ There are a number of challenges with implementation, however. First, national data suggest that the performance of CDST after Xpert detection of RMP resistance is poor, although this has not been formally studied. Second, records indicate that not all patients diagnosed with MDR-TB are initiated on treatment. Loss to follow-up between the initial diagnosis of $\mathrm{TB}$ and the start of treatment is known as 'initial loss to follow-up' (formerly termed 'initial default'), and is well recognised to occur when sputum smears are used for diagnosis. ${ }^{11-13}$ More information is needed about what occurs between the diagnosis of MDR-TB and subsequent treatment, and improving this linkage is a key priority of the WHO End TB control strategy. ${ }^{14}$ Third, several sites in Zimbabwe have been repeating Xpert assays on the same patient following an initial RMP-resistant Mycobacterium tuberculosis result, which may inadvertently add to the numbers of reported initial losses to follow-up and unnecessarily increase the consumption of expensive Xpert cartridges (approximately US $\$ 10$ per cartridge). More information about these challenges will help the National Tuberculosis Programme (NTP) in Zimbabwe, as well as in other countries, to develop better strategic use of Xpert.

The aim of this study was to assess the linkage between diagnostic and treatment services for patients investigated and diagnosed with RMP-resistant TB using Xpert in two provinces in Zimbabwe (Manicaland and Harare City) in 2014. Specific objectives were to determine 1) the Xpert assays performed and the number and proportion showing resistance to RMP (including repeat assays), and 2) the number of patients identified with RMP resistance by Xpert; the number and proportion who had CDST performed along with the results; the number and proportion of patients who never started MDR-TB treatment and the
AFFILIATIONS

1 International Union

Against Tuberculosis and Lung Disease (The Union), Harare, Zimbabwe

2 The Union, Paris, France

3 National Tuberculosis

Programme, Cotonou,

Benin

4 London School of Hygiene

\& Tropical Medicine,

London, UK

5 Ministry of Health and

Child Care, Harare,

Zimbabwe

6 Harare City Health

Department, Harare, Zimbabwe

CORRESPONDENCE

Kelvin Charambira

International Union Against

Tuberculosis and Lung

Disease

13 Van Praagh Avenue

Milton Park

Harare

(263) Zimbabwe

e-mail: kcharambira@

theunion.org

KEY WORDS

tuberculosis; MDR-TB; RMP resistance; Xpert MTB/RIF; culture and drug

susceptibility testing; SORT

Received 11 January 2016 Accepted 18 February 2016

PHA2016;6(2):122-128 (c) 2016 The Union 
reasons why; and, among those who did start treatment, the time taken to initiate MDR-TB treatment.

\section{METHODS}

\section{Study design}

This was a retrospective cross-sectional study of Xpert and a cohort study using routinely collected data to follow patients through the process of CDST and MDR-TB treatment.

\section{General setting and study sites}

Country and provinces

Zimbabwe is a landlocked country in southern Africa with an estimated population of 15 million and a gross domestic product of US\$830 per capita in 2013.15 The study was conducted in two provinces, Harare City and Manicaland, which have populations of approximately 2 million and 1.8 million, respectively. ${ }^{16}$ Public health services in the two provinces are discharged through the City Health Department and the Provincial Health Directorate. Xpert instruments were made available in the provinces in 2012 and 2013, and by December 2014, nine Xpert instruments were available in each of the two provinces.

\section{The National Tuberculosis Programme and management of presumed MDR-TB}

The management of MDR-TB in Zimbabwe is coordinated through a designated national MDR-TB focal person, and there is a committee in each province and district to oversee the clinical and programmatic management of MDR-TB. The committees have the mandate of initiating patients on MDR-TB treatment as soon as possible.

Patients are deemed to have suspected MDR-TB if they are symptomatic and 1) have failed to sputum smear convert at 2 months during first-line anti-tuberculosis treatment, 2) have a history of previous anti-tuberculosis treatment, 3) are contacts of a known index patient with MDR-TB, 4) have travelled from a high MDR-TB burden country, or 5) have come from highrisk congregate settings such as prisons. It is recommended that these patients and those with HIV-associated presumptive $\mathrm{TB}$ have Xpert performed on one sputum specimen.

The Xpert assay results are recorded in the registers of the nine laboratories in Harare City and the nine laboratories throughout the province of Manicaland. If the Xpert assay shows M. tuberculosis and RMP resistance, further sputum specimens should be submitted for CDST at the Harare-based National Microbiology Reference Laboratory (NMRL). Once diagnosed with RMP-resistant TB by Xpert, all patients should start MDR-TB treatment immediately using standardised recommended regimens. ${ }^{17}$ These regimens consist of five drugs (kanamycin [KM], levofloxacin [LVX], cycloserine [CS], ethionamide [ETH] and pyrazinamide [PZA]) for the initial phase of 6-8 months, followed by four drugs (LVX, CS, ETH and PZA) for the continuation phase of 14 months. The initial phase is administered either in hospital or at home and is directly observed, while the continuation phase is administered from home. Prior to treatment, the district MDR-TB committee discusses the model of care to be used in the management of the patient, whether as an out-patient or an in-patient for the initial phase. The latter model is only used for very ill patients or when infection control is not achievable at home. Baseline biochemical tests are then conducted before treatment is initiated.

\section{Study population}

All patients who were tested using Xpert and registered in the laboratory registers in the Harare City and Manicaland provinces between January and December 2014 were included in the study.

\section{Data variables, sources of data, data collection tools and data validation}

Data variables were collected from the Xpert laboratory registers and archive files, the CDST register in the Harare NMRL and the MDR-TB treatment registers. To follow the process of CDST, the names of those found to have M. tuberculosis or RMP resistance detected in the Xpert registers were searched for in the NMRL register in Harare for up to 6 months after the last patient was registered in the Xpert laboratory registers.

For data validation, Xpert results in the laboratory registers were cross-checked with data extracted from the Xpert machines, and data in the treatment registers were cross-checked with facility-based patient medical files. Study data were collected into paper-based questionnaires between March and November 2015.

\section{Analysis and statistics}

Data from the paper-based questionnaires were double entered and analysed using EpiData software (version 3.1 for entry and version 2.2.2.182 for analysis, EpiData Association, Odense, Denmark). Data were analysed by frequencies and percentages, with comparisons between the two provinces and between patient categories assessed using the $\chi^{2}$ test, risk ratios and 95\% confidence intervals (CI). Levels of significance were set at $5 \%$

\section{Ethics}

Permission for the study was obtained from the NTP and the Medical Research Council, Harare, Zimbabwe. The study met the Médecins Sans Frontières (MSF) Ethics Review Board (Geneva, Switzerland) approved criteria for studies of routinely collected data and was approved by the Ethics Advisory Group of the International Union Against Tuberculosis and Lung Disease, Paris, France. As this was a record review study with anonymised data, informed patient consent was not required.

\section{RESULTS}

\section{Xpert assays}

The number of Xpert assays performed and their results in both Harare and Manicaland provinces in 2014 are shown in Figure 1. Of 20329 assays performed in both provinces, 90\% were successful, and of these, $11 \%$ detected M. tuberculosis. There were 97
ACKNOWLEDGEMENTS This research was conducted through the Structured Operational Research and Training Initiative (SORT IT), a global partnership led by the Special Programme for Research and Training in Tropical Diseases at the World Health Organization (WHO/TDR). The model is based on a course developed jointly by the International Union Against Tuberculosis and Lung Disease (The Union), Paris, France, and Médecins Sans Frontières (MSF), Brussels Operational Centre, Luxembourg. The specific SORT IT programme that resulted in this publication was jointly developed and implemented by the Operational Research Unit (LUXOR), MSF; the Centre for Operational Research, The Union; the Centre for International Health, University of Bergen, Bergen, Norway; the Institute of Tropical Medicine, Antwerp, Belgium and Partners in Health,

Boston, MA, USA

The programme was funded by The Union, MSF, and the Department for International Development, London, UK. The funders had no role in the study design, data collection and analysis, decision to publish, or preparation of the manuscript. La Fondation Veuve Emile Metz-Tesch, Luxembourg, also supported open access publication costs.

Conflicts of interest: none declared.

In accordance with the WHO's open-access publication policy for all work funded by the WHO or authored/co-authored by WHO staff members, the WHO retains the copyright of this publication through Creative Commons Attribution IGO licence (http://creativecommons. org/licenses/by/3.0/igo/ legalcode), which permits unrestricted use, distribution and reproduction in any medium provided the original work is properly cited. 


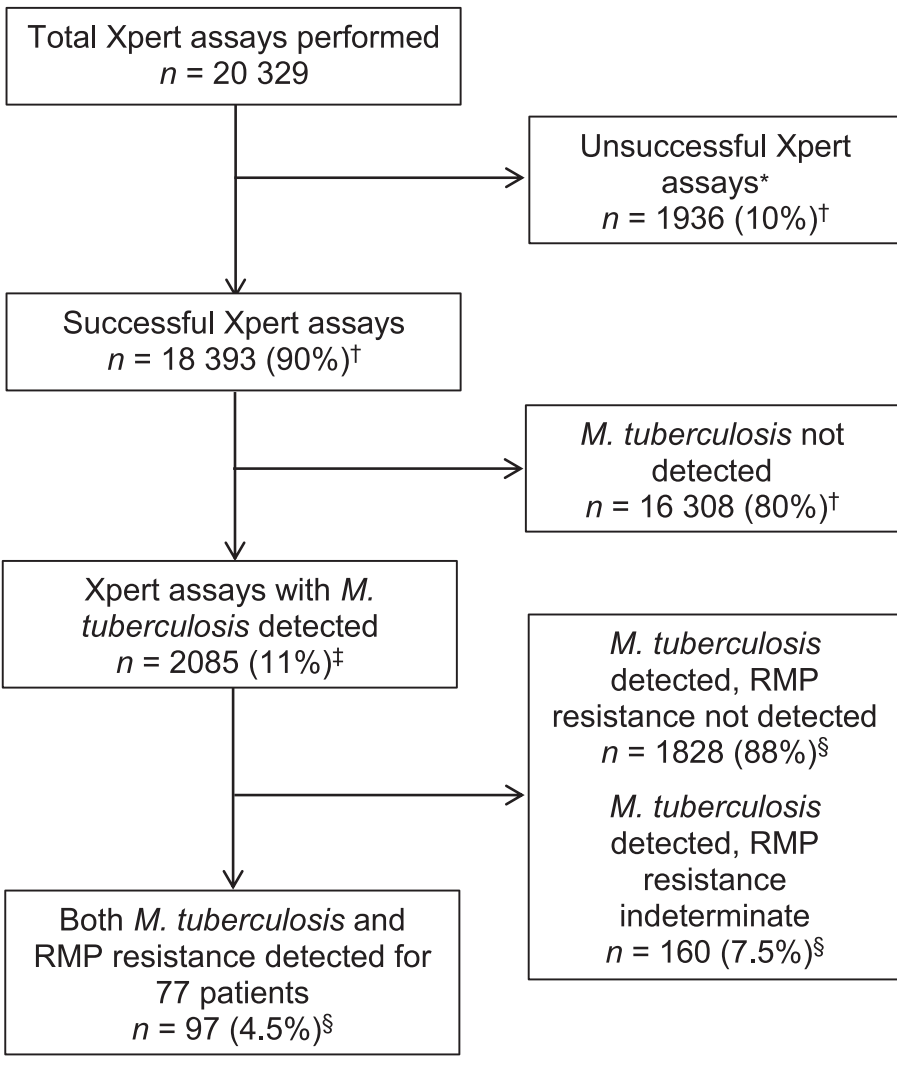

FIGURE 1 Xpert ${ }^{\circledR}$ MTB/RIF assays performed and results in both Harare and Manicaland provinces, Zimbabwe, 2014. * Unsuccessful test $=$ error result, invalid or no result. ${ }^{\dagger}$ Denominator $=$ total Xpert assays performed. ‡Denominator $=$ successful Xpert assays. $\$$ Denominator $=$ Xpert assays with $M$. tuberculosis detected. RMP = rifampicin.

assays (4.5\% of those detecting $M$. tuberculosis) that showed RMP resistance. A comparison between Harare and Manicaland of the number of assays performed and their results is shown in Table 1. There were some programmatic differences between the two sites: the proportion of assays detecting M. tuberculosis was higher in Harare, but the proportion of M. tuberculosis assays that showed RMP resistance was higher in Manicaland. Altogether, of 77 patients who had RMP resistance on Xpert, 60 had one Xpert assay, 14 had two assays and 3 had three assays. Thus, 17 (22\%) patients with RMP resistance had two or more assays done.

\section{Patients with rifampicin resistance on Xpert and CDST results}

Of the 77 patients who were RMP-resistant on Xpert, the outcomes of sending samples to the NMRL for CDST for both provinces combined are shown in Figure 2. There were losses at almost all stages. Of the 77 patients, $70 \%$ had samples sent to the reference laboratory for CDST; 53\% of the samples arrived and were registered at the reference laboratory; $21 \%$ of these showed growth of M. tuberculosis; and $17 \%(n=13)$ had a DST result recorded. All 13 patients were RMP-resistant, and 11 were also INH-resistant. The outcomes of sending samples for CDST in Harare compared with Manicaland are shown in Table 2. There were no significant differences at any stage between the two provinces.

\section{MDR-TB treatment initiation in rifampicin-resistant patients on Xpert}

Of the 77 patients detected with RMP-resistant M. tuberculosis, 34 (44\%) were never initiated on MDR-TB treatment. Reasons for never starting MDR-TB treatment are shown in Table 3. In two thirds of the patients there was no documented reason. Starting a first-line anti-tuberculosis treatment regimen, loss to follow-up and death were the three documented reasons for not starting appropriate treatment. Sex, HIV status, category of TB and the province where the diagnosis was made were not associated with never starting MDR-TB treatment (see Table 4).

For the 43 patients who initiated MDR-TB treatment, the time from diagnosis to treatment initiation in both provinces is shown in Table 5. Most patients (71\% in Harare and 65\% in Manicaland) were initiated on treatment within 2 weeks of diagnosis. There were no significant differences in the time from diagnosis to treatment initiation in the provinces.

TABLE 1 Number of Xpert ${ }^{\circledR}$ MTB/RIF assays performed and the results in Harare and Manicaland provinces, Zimbabwe, 2014

\begin{tabular}{lccc}
\hline & Harare & Manicaland & \\
Xpert assays and results & $n(\%)$ & $n(\%)$ & $P$ value \\
\hline Xpert assays performed & 13384 & 6945 & \\
Successful Xpert assays & $12149(91)$ & $6244(90)$ & 0.02 \\
Xpert assays with M. tuberculosis detected & $1129(9)$ & $956(15)$ & $<0.001$ \\
Xpert assays with M. tuberculosis detected that showed: & & & \\
RMP-susceptible bacilli & $1012(90)$ & $816(85)$ & $<0.001$ \\
RMP-resistant bacilli & $36(3)$ & $61(6)$ & 0.001 \\
RMP-indeterminate bacilli & $81(7)$ & $79(8)$ & 0.41 \\
Unsuccessful Xpert assays & $1235(9)$ & $701(10)$ & 0.02 \\
Error results* & $857(69)$ & $423(60)$ & $<0.001$ \\
No results & $276(22)$ & $195(28)$ & 0.003 \\
Invalid results & $101(8)$ & $84(12)$ & 0.004 \\
\hline
\end{tabular}

*Error results: probe check control failed and the assay was aborted due to the following: 1) the reaction tube being filled improperly; 2) a reagent probe integrity problem detected; 3 ) the maximum pressure limits were exceeded; 4) an Xpert module failure.

$\dagger$ No results: insufficient data were collected due to 1 ) power failure; 2 ) test stopped by the operator.

\#Invalid results: presence or absence of $M$. tuberculosis could not be determined due to the following: 1) sample processing control did not meet acceptance criteria; 2 ) sample was not properly processed; 3) PCR was inhibited. $\mathrm{RMP}=$ rifampicin; $\mathrm{PCR}=$ polymerase chain reaction . 


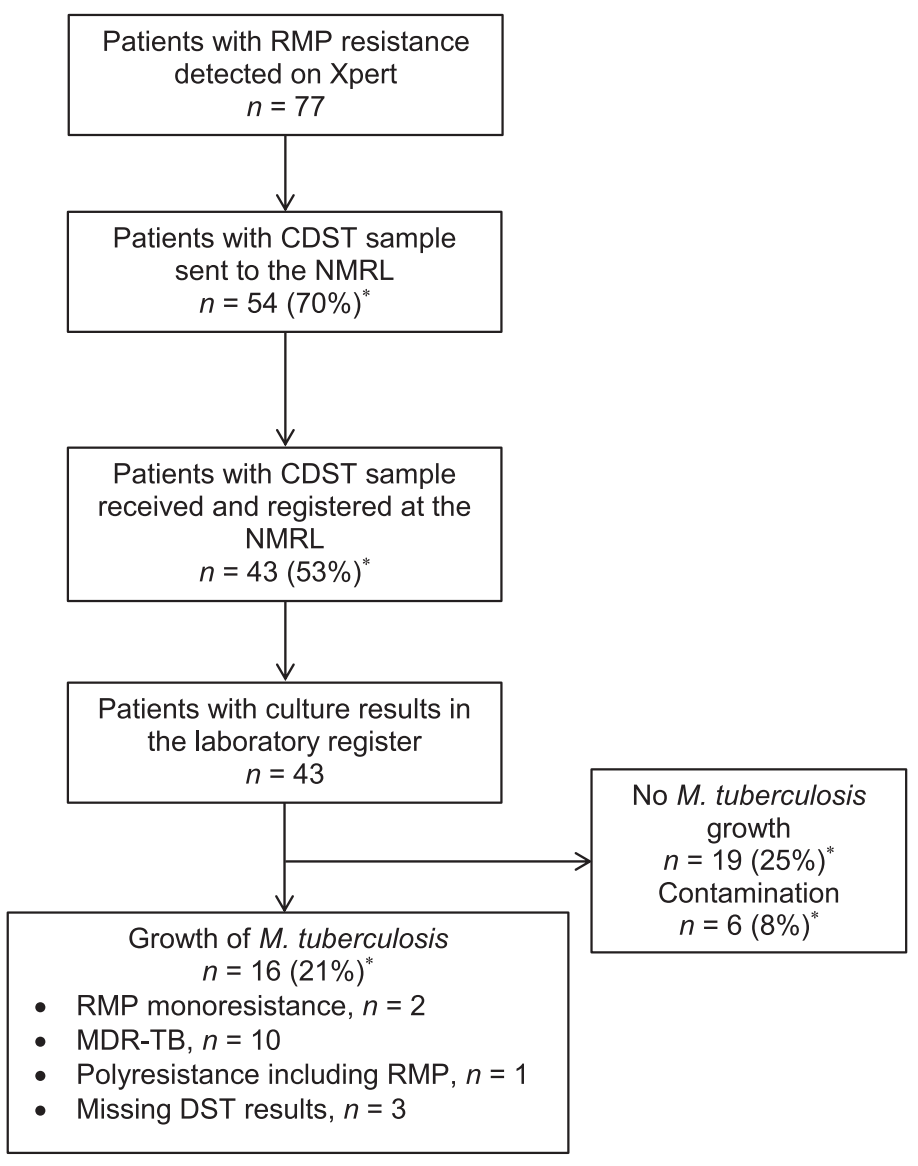

FIGURE 2 Patients with RMP resistance on Xpert ${ }^{\circledR}$ MTB/RIF and process and performance of CDST in both Harare and Manicaland provinces, Zimbabwe, 2014. * Denominator = patients diagnosed RMP-resistant on Xpert. RMP = rifampicin; CDST = culture and drug susceptibility testing; NMRL = National Microbiology Reference Laboratory; MDR-TB $=$ multidrug-resistant tuberculosis; DST $=$ drug susceptibility testing.

\section{DISCUSSION}

This is the first study in Zimbabwe to assess linkages between diagnosis and treatment for patients detected with RMP-resistant TB using Xpert. There were some important findings. First, large numbers of Xpert assays were successfully performed in the two
TABLE 3 Reasons for never starting MDR-TB treatment in patients with RMP resistance on Xpert ${ }^{\circledR}$ MTB/RIF in both Harare and Manicaland provinces, Zimbabwe, 2014

\begin{tabular}{lc}
\hline Reason for never starting MDR-TB treatment & $n(\%)$ \\
\hline Started treatment with first line anti-tuberculosis drugs & $5(15)$ \\
Lost to follow-up & $3(9)$ \\
Death & $4(12)$ \\
Not documented & $22(64)$ \\
Total & 34 \\
\hline MDR-TB = multidrug-resistant tuberculosis; RMP = rifampicin; TB = tuberculosis.
\end{tabular}

provinces in the 12 -month period studied. Nearly 5\% of M. tuberculosis strains showed resistance to RMP, and repeat tests were performed in about one fifth of these patients, although we have no information about why the tests were repeated.

Second, the process of sending specimens and obtaining CDST results was poor, with only one fifth of the patients detected with RMP-resistant strains on Xpert being confirmed by CDST. On a positive note, when CDST was performed successfully, all those with RMP resistance on Xpert were also confirmed as having RMP resistance in the reference laboratory.

Third, almost half of the patients detected with RMP resistance on Xpert never started MDR-TB treatment, and the reasons were often not documented. Finally, about one third of those who did begin MDR-TB treatment had a treatment delay of $>2$ weeks from the date of diagnosis.

The strengths of this study were that it included all Xpert assays performed in the two provinces during a 12-month period, and included all patients detected with RMP-resistant TB. There was therefore no need for any sampling framework. The study was conducted under routine programmatic conditions, and adhered to the Strengthening the Reporting of Observational Studies in Epidemiology (STROBE) guidelines for conducting and reporting on observational studies. ${ }^{18}$ Limitations included the retrospective nature of the study using already collected secondary data in registers and archived Xpert files, where some data are missing and some may be inaccurately recorded.

There are some important lessons to be learnt. The high success rate of the Xpert assays in our programmatic setting study compares favourably with recent results reported from a national programme study in nearby Swaziland, although the proportion

TABLE 2 Patients resistant to RMP on Xpert ${ }^{\circledR}$ MTB/RIF and the process and performance of CDST at the Harare-based NMRL, Harare and Manicaland provinces, Zimbabwe, 2014

\begin{tabular}{lccc}
\hline Characteristics & $\begin{array}{c}\text { Harare } \\
n(\%)\end{array}$ & $\begin{array}{c}\text { Manicaland } \\
n(\%)\end{array}$ & $P$ value \\
\hline Patients with RMP-resistant TB strains & 35 & 42 & \\
Patients with CDST sample sent to the NMRL & $22(63)$ & $32(76)$ & 0.20 \\
Patients with CDST sample received and registered at the NMRL & $19(54)$ & $22(52)$ & 0.86 \\
Patients with CDST results in the NMRL register & $19(54)$ & $22(52)$ & 0.86 \\
Culture results & & & \\
$\quad$ No growth & $10(29)$ & $9(21)$ & 0.47 \\
M. tuberculosis growth* & $5(14)$ & $11(26)$ & 0.20 \\
$\quad$ Contamination & $4(11)$ & $2(5)$ & 0.51 \\
CDST results received by the referring facility & $16(46)$ & $17(40)$ & 0.64 \\
\hline
\end{tabular}

*DST showed: RMP monoresistance $(n=2)$; MDR $(n=10)$; polydrug resistance, including RMP $(n=1)$; missing DST results $(n=3)$.

RMP = rifampicin; CDST = culture and drug susceptibility testing; NMRL = National Microbiology Reference Laboratory; TB = tuberculosis; MDR = multidrug resistance; DST = drug susceptibility testing. 
TABLE 4 Factors associated with never starting MDR-TB treatment in patients with RMP resistance on Xpert $^{\circledR}$ MTB/RIF in both Harare and Manicaland, Zimbabwe, 2014

\begin{tabular}{|c|c|c|c|c|}
\hline Characteristics & $\begin{array}{l}\text { Patients with RMP } \\
\text { resistance on } \\
\text { Xpert } \\
n\end{array}$ & $\begin{array}{c}\text { Patients who never } \\
\text { started MDR-TB } \\
\text { treatment } \\
n(\%)\end{array}$ & RR & $P$ value \\
\hline Total & 77 & $34(44)$ & & \\
\hline \multicolumn{5}{|l|}{ Sex } \\
\hline Female & 31 & $6(19)$ & 1 & \\
\hline Male & 27 & $9(33)$ & $\begin{array}{c}1.7 \\
(0.7-4.2)\end{array}$ & 0.22 \\
\hline Missing data & 19 & $19(100)$ & - & \\
\hline \multicolumn{5}{|l|}{ HIV status } \\
\hline Negative & 15 & $3(20)$ & 1 & \\
\hline Positive & 35 & $7(20)$ & $\begin{array}{c}1.0 \\
(0.3-3.4)\end{array}$ & 0.04 \\
\hline Unknown & 27 & $24(89)$ & - & \\
\hline \multicolumn{5}{|l|}{ Category of TB } \\
\hline Retreatment & 23 & $2(9)$ & 1 & \\
\hline New & 27 & $6(22)$ & $\begin{array}{c}2.6 \\
(0.6-11.5)\end{array}$ & 0.26 \\
\hline Missing data & 26 & $27(92)$ & - & \\
\hline \multicolumn{5}{|l|}{ Province } \\
\hline Manicaland & 42 & $16(38)$ & 1 & \\
\hline Harare & 35 & $18(51)$ & $\begin{array}{c}1.4 \\
(0.8-2.2)\end{array}$ & 0.24 \\
\hline
\end{tabular}

MDR-TB = multidrug-resistant tuberculosis; $\mathrm{RMP}=$ rifampicin; $\mathrm{RR}=$ risk ratio; $\mathrm{Cl}=$ confidence interval; HIV = human immunodeficiency virus; $\mathrm{TB}=$ tuberculosis.

of unsuccessful assays in Zimbabwe was higher than in Swaziland. ${ }^{19}$

The system of sending sputum specimens and receiving the results back between the peripheral health facilities and the central reference laboratory in Harare did not work. At each stage there were losses, and when the specimens finally did arrive at the laboratory, over half failed to successfully grow M. tuberculosis. This problem of sending samples to a central reference laboratory is not unique to Zimbabwe; similar challenges are encountered in many other countries. ${ }^{20-24}$ Trying to fix these challenges is also not easy, as described in a case study from Malawi. ${ }^{20}$ As several studies, including our own, have highlighted the high sensitivity and specificity of Xpert compared with phenotypic CDST under routine programme settings, $, 9,25$ we question the need for CDST to confirm RMP-resistant TB. CDST might be better used 1) to diagnose resistance to second-line anti-tuberculosis results and thus help to diagnose extensively drug resistant (XDR) TB (MDR-TB that is also resistant to both any fluoroquinolone and one of the injectable second-line drugs) or pre-XDR-TB (MDR-TB resistant to either any fluoroquinolone or one of the injectable second-line drugs); and 2) to follow up patients who are failing MDR-TB treatment.

It is unacceptable for any patient diagnosed with MDR-TB never to start treatment or to start treatment after several weeks of delay. Again, this problem is not unique to Zimbabwe. Of the 300000 notified TB patients estimated to have MDR-TB globally in 2014, only 110000 (37\%) started MDR-TB treatment, and of these, only $50 \%$ successfully completed treatment. ${ }^{26}$ Possible reasons for delays in starting treatment in Zimbabwe might be the time taken in conducting the baseline biochemistry tests on liver and renal function and the decision to start MDR-TB treatment, which is made by the clinical management team. Previous studies
TABLE 5 Time from diagnosis to MDR-TB treatment among patients with RMP resistance detected using Xpert ${ }^{\circledR}$ MTB/RIF in both Harare and Manicaland provinces, Zimbabwe, 2014

\begin{tabular}{lccc}
\hline $\begin{array}{l}\text { Time from diagnosis to } \\
\text { treatment initiation, days }\end{array}$ & $\begin{array}{c}\text { Harare } \\
n(\%)\end{array}$ & $\begin{array}{c}\text { Manicaland } \\
n(\%)\end{array}$ & $P$ value \\
\hline $0-14$ & $12(71)$ & $17(65)$ & 0.72 \\
$15-28$ & $2(12)$ & $4(15)$ & 0.91 \\
$>28$ & $1(6)$ & $2(8)$ & 0.70 \\
Unknown & $2(12)$ & $3(12)$ & 0.64 \\
$\quad$ Total & 17 & 26 & \\
\hline
\end{tabular}

MDR-TB = multidrug-resistant tuberculosis; RMP = rifampicin .

conducted elsewhere have shown that delayed treatment is due to a combination of patient and health system factors, ${ }^{27-29}$ and these need to be addressed.

This study has several implications for the NTP. First, Xpert instruments need to be functional at all times, with unsuccessful tests reduced to a minimum. This means attention by the NTP to maintenance, calibration, uninterrupted power supplies and consistent external back-up of data. Second, we suggest that the current recommendations of using CDST for confirming Xpert RMP resistance be revised. Third, all patients who are diagnosed with MDR-TB must start MDR-TB treatment. The process of initiating a patient on MDR-TB treatment after diagnosis is quite complicated in Zimbabwe, requiring biochemical tests that may not always be available at the clinical level and a decision by a specific committee; all of these steps may delay the start of treatment. This process needs to be reviewed to see whether it can be simplified. Also, instead of evaluating treatment outcomes on those registered for treatment, it would be better and more honest, as suggested previously, 12,13 to evaluate outcomes in those diagnosed with MDR-TB and recording as a treatment outcome 'initial loss to follow-up'. Finally, we need qualitative research to better understand why some patients do not start MDR-TB treatment.

In conclusion, although the roll-out of Xpert technology in two provinces in Zimbabwe has been successful, there were shortcomings with respect to the central reference laboratory confirmation of RMP-resistant TB diagnosis and the timely linkage of patients to MDR-TB treatment. These shortcomings must be addressed. With the international community signed up to end the TB epidemic by 2030,30 attention to these programme issues will be essential if this goal is to be realised.

\section{References}

1 World Health Organization. Global tuberculosis report 2014. WHO/HTM/ TB/2014.08. Geneva, Switzerland: WHO, 2014.

2 Zimbabwe Ministry of Health and Child Care. Zimbabwe National and Sub-National HIV and AIDS Estimates 2014. Harare, Zimbabwe: Ministry of Health and Child Care, 2014.

3 Reid M J A, Shah N S. Approaches to tuberculosis screening and diagnosis in people with HIV in resource-limited settings. Lancet Infect Dis 2009; 9: 173184.

4 Lawn S D, Wood R. Tuberculosis in antiretroviral treatment services in resource-limited settings: addressing the challenges of screening and diagnosis. J Infect Dis 2011; 204 (Suppl 4): S1159-S1167.

5 Harries A D, Zachariah R, Corbett E L, et al. The HIV-associated tuberculosis epidemic-when will we act? Lancet 2010; 375: 1906-1919.

6 Boehme C C, Nabeta P, Hillemann D, et al. Rapid molecular detection of tuberculosis and rifampin resistance. N Engl J Med 2010; 363: 1005-1015.

7 Boehme C C, Nicol M P, Nabeta P, et al. Feasibility, diagnostic accuracy, and effectiveness of decentralised use of the Xpert MTB/RIF test for diagnosis of tuberculosis and multidrug resistance: a multicentre implementation study. Lancet 2011; 377: 1495-1505.

8 World Health Organization. Policy statement: automated realtime nucleic acid amplification technology for rapid and simultaneous detection of tu- 
berculosis and rifampicin resistance: Xpert MTB/RIF system. WHO/HTM/ TB/2011.4. Geneva, Switzerland: WHO, 2011.

9 World Health Organization. Rapid implementation of the Xpert MTB/RIF diagnostic test. Technical and operational 'how-to'. Practical considerations. WHO/HTM/TB/2011. Geneva, Switzerland: WHO, 2011.

10 World Health Organization. Xpert MTB/RIF assay for diagnosis of pulmonary and extra-pulmonary TB in adults and children. 2013. Policy update. WHO/HTM/TB/2013.16. Geneva, Switzerland: WHO, 2013.

11 Botha E, Den Boon S, Verver S, et al. Initial default from tuberculosis treatment: how often does it happen and what are the reasons? Int J Tuberc Lung Dis 2008; 12: 820-823.

12 Afutu F K, Zachariah R, Hinderaker S G, et al. High initial default in patients with smear-positive pulmonary tuberculosis at a regional hospital in Accra, Ghana. Trans R Soc Trop Med Hyg 2012; 106: 511-513.

13 Harries A D, Rusen I D, Chiang C-Y, Hinderaker S G, Enarson D A. Registering initial defaulters and reporting on their treatment outcomes. Int J Tuberc Lung Dis 2009; 13: 801-803.

14 World Health Organization. WHO End TB Strategy. Global strategy and targets for tuberculosis prevention, care and control after 2015. Geneva, Switzerland: WHO, 2015. http://www.who.int/tb/post2015_strategy/en/ Accesssed February 2016

15 The World Bank. Working for a world free of poverty. Washington, DC, USA: World Bank, 2015. http://data.worldbank.org/country/zimbabwe Accessed February 2016

16 Zimbabwe National Statistics Agency. Census 2012. Preliminary Report. Harare, Zimbabwe: National Statistics Agency, 2012.

17 World Health Organization. Companion handbook to the WHO guidelines for the programmatic management of drug resistant tuberculosis. WHO/ HTM/TB.2014.11. Geneva, Switzerland: WHO, 2014.

18 von Elm E, Altman D G, Egger M. The Strengthening the Reporting of Observational Studies in Epidemiology (STROBE) statement: guidelines for reporting observational studies. Bull World Health Organ 2007; 85: 867872 .

19 Sikhondze W, Dlamini T, Khumalo D, et al. Countrywide roll-out of Xpert ${ }^{\circledR}$ MTB/RIF in Swaziland: the first three years of implementation. Public Health Action 2015; 5: 140-146.
20 Harries A D, Michongwe J, Nyirenda T E, et al. Using a bus service for transporting sputum specimens to the Central Reference Laboratory: effect on the routine TB culture service in Malawi. Int J Tuberc Lung Dis 2004; 8: 204210

21 Kilale A M, Ngowi B J, Mfinanga G S, et al. Are sputum samples of retreatment tuberculosis reaching the reference laboratories? A 9-year audit in Tanzania. Public Health Action 2013; 3: 156-159.

22 Chadha S S, Sharath B N, Reddy K, et al. Operational challenges in diagnosing multi-drug resistant TB and initiating treatment in Andhra Pradesh, India. PLOS ONE 2011; 6: e26659.

23 Qi W, Harries A D, Hinderaker S G. Performance of culture and drug susceptibility testing in pulmonary tuberculosis patients in northern China. Int J Tuberc Lung Dis 2011; 15: 137-139.

24 Tharu M B, Harries A D, Goel S, et al. Screening retreatment tuberculosis patients for drug resistance in mid-west Nepal: how well are we doing? Public Health Action 2014; 4: 60-65.

25 van Kampen S C, Tursynbayeva A, Koptleuova A, et al. Effect of introducing Xpert MTB/RIF to test and treat individuals at risk of multidrug-resistant tuberculosis in Kazakhstan: a prospective cohort study. PLOS ONE 2015; 10: e0132514.

26 World Health Organization. Global tuberculosis report 2015. WHO/HTM/ TB/2015.22. Geneva, Switzerland: WHO, 2015.

27 Rifat M, Hall J, Oldmeadow C, Husain A, Milton A H. Health system delay in treatment of multidrug resistant tuberculosis patients in Bangladesh. BMC Infect Dis 2015; 15: 526

28 Takarinda K C, Harries A D, Nyathi B, Ngwenya M, Mutasa-Apollo T, Sandy C. Tuberculosis treatment delays and associated factors within the Zimbabwe national tuberculosis programme. BMC Public Health 2015; 15: 29.

29 Naidoo P, van Niekerk M, du Toit E, et al. Pathways to multidrug-resistant tuberculosis diagnosis and treatment initiation: a qualitative comparison of patients' experiences in the era of rapid molecular diagnostic tests. BMC Health Services Research 2015; 15: 488.

30 United Nations. Transforming our world: the 2030 agenda for sustainable development. New York, NY, USA: United Nations, 2015. http:// sustainabledevelopment.un.org/post2015/transformingourworld Accessed February 2016
Contexte : Au Zimbabwe, la prise en charge des patients tuberculeux ayant une résistance à la rifampicine (RMP) diagnostiqués par Xpert ${ }^{\circledR}$ MTB/RIF est préoccupante.

Objectif : Evaluer les liens entre le diagnostic et le traitement de ces patients dans les provinces de Harare et de Manicaland en 2014.

Schéma : Etude rétrospective de cohorte.

Résultats : Sur 20329 tests Xpert, 90\% ont été réussis, 11\% ont détecté Mycobacterium tuberculosis et $4,5 \%$ ont mis en évidence une résistance à la RMP. II y a eu 77 patients atteints d'une tuberculose (TB) résistante à la RMP diagnostiqués par Xpert. Parmi eux, $70 \%$ ont bénéficié d'un envoi d'échantillon au laboratoire de référence pour une culture et un test de pharmacosensibilité (CDST) ; pour 53\% d'entre eux, les échantillons sont arrivés à bon port ; pour 21\%, les échantillons ont mis en évidence une croissance de $M$. tuberculosis; et chez $17 \%$, les résultats du CDST ont été enregistrés et tous ont confirmé la résistance à la RMP. Sur 77 patients, 34 (44\%) n'ont jamais mis en route un traitement pour le TB multirésistante (TB-MDR) ; les motifs documentés étaient le décès, la perte de vue ou un traitement incorrect. Des 43 patients qui ont débuté le traitement de TB-MDR, $12(71 \%)$ à Harare et 17 (65\%) au Manicaland ont commencé dans les 2 semaines suivant le diagnostic.

Conclusion : L'Xpert a été lancé avec succès dans deux provinces du Zimbabwe. Cependant, le processus de confirmation du CDST pour une TB résistante à la RMP diagnostiquée par Xpert ne fonctionne pas bien, et de nombreux patients sont soit traités avec retard, soit ne démarrent jamais le traitement de TB-MDR. Ces problèmes doivent être examinés par le programme. 
Marco de referencia: En Zimbabwe, el tratamiento de los pacientes cuyo diagnóstico de tuberculosis (TB) resistante a la rifampicina (RMP) se determina mediante la prueba Xpert $^{\circledR}$ MTB/RIF es fuente de inquietud.

Objetivo: Evaluar los nexos entre el diagnóstico y el tratamiento de los pacientes diagnosticados mediante la prueba Xpert en las provincias de Harare y Manicaland en el 2014.

Método: Fue este un estudio retrospectivo de cohortes.

Resultados: Se obtuvieron resultados satisfactorios en el $90 \%$ de las 20329 pruebas Xpert realizadas; se detectó Mycobacterium tuberculosis en el $11 \%$ y el $4,5 \%$ reveló resistencia a RMP. Con la prueba Xpert se diagnosticaron 77 casos de TB resistente a RMP y se enviaron muestras del $70 \%$ de estos casos al laboratorio de referencia, con el fin de practicar el cultivo y las pruebas se sensibilidad (CDST) a los medicamentos antituberculosos. El 53\% de estas muestras llegaron al laboratorio, en un $21 \%$ se obtuvo crecimiento de $M$. tuberculosis y en el $17 \%$ de los casos existía un registro de los resultados de la CDST; todos los resultados confirmaron la resistencia a RMP. De los 77 pacientes, 34 nunca comenzaron el tratamiento contra la TB multidrogorresistente (TB-MDR) (44\%); las causas documentadas fueron el fallecimiento, la pérdida durante el seguimiento y un tratamiento inadecuado. De los 43 pacientes que iniciaron el tratamiento por TB-MDR, 12 casos en Harare (71\%) y 17 casos en Manicaland (65\%) lo comenzaron en las 2 primeras semanas después del diagnóstico.

Conclusión: El despliegue de la prueba Xpert en dos provincias de Zimbabwe fue satisfactorio. Sin embargo, el mecanismo de confirmación de la resistencia a RMP mediante el CDST en los casos diagnosticados por la prueba Xpert fue deficiente y en muchos pacientes se retrasó el tratamiento de la TB-MDR o nunca se comenzó. Es preciso abordar estas deficiencias en el marco programático.
Public Health Action (PHA) The voice for operational research. Published by The Union (www.theunion.org), PHA provides a platform to fulfil its mission, 'Health solutions for the poor'. PHA publishes high-quality scientific research that provides new knowledge to improve the accessibility, equity, quality and efficiency of health systems and services.
e-ISSN 2220-8372

Editor-in-Chief: Dermot Maher, MD, Switzerland Contact: pha@theunion.org

PHA website: http://www.theunion.org/what-we-do/journals/pha Article submission: http://mc.manuscriptcentral.com/pha 